\title{
Analysis of Spatial and Temporal Distribution Characteristics of Dust Storm in Inner Mongolia in Recent 30 Years
}

\author{
Terigele, Yongmei*, Yinshan, \\ Inner Mongolia Normal University College of Geographical Sciences,Hohhot,010022, China; \\ 近 30 年内蒙古沙尘暴时空分布特征分析
}

特日格乐, 咏梅", 银山,

内蒙古师范大学 地理科学学院, 呼和浩特, 010022

\begin{abstract}
In this study, using the technology of statistical and geographic information system as the main research methods study characteristics of temporal and spatial distribution of Sandstorm in Inner Mongolia, by analyzing from the characteristics of a wide range of dust weather and through on a longer time scale dust storms moving path of observation and statistical analysis, has important scientific significance and research value. The results showed that: (1) in the recent 35 years, the number of sand dust storm days in Inner Mongolia showed a decreasing trend. Among them, the change of each time, the main high frequency hair period for 1980s and twenty-first Century. (2) in recent 30 years in Inner Mongolia 42 stations in 1981-2014 spatial distribution characteristics of sandstorm is decreasing from west to east. 1980-1999 sandstorms in Inner Mongolia high frequency area mainly concentrated in the Alashan Guaizi lake and Haili (two; in 2000 after the territory of Inner Mongolia appeared new sandstorm frequently occurred region, Inner Mongolia Sonid Left Banner, Xilin Gol League and the surrounding area. In 2001-2014 sand dust storm high incidence area mainly in Guaizi
\end{abstract}

*通讯作者: 咏梅, yongmei201101@gmail.com lake, Haili of Sonid Left Banner, as the center. The number of sand dust storms occurred in the three regions accounted for $90 \%$ of the frequency of the region, which accounted for 12 of the sites in Xilinguole Meng, the number of days accounted for more than $50 \%$. This and the characteristics of the underlying surface and climate conditions have close relationship, the area of desert sand, gale, multiple and wind speed is high, vegetation coverage is low; occurs in eastern Inner Mongolia and northeast area is the minimum number of times, namely Hulunbeier and Hinggan League, where vegetation cover is good, the average annual rainfall of highest surface sand is not easy to wind was blowing and causing sandstorms.

Keywords: Sandstorm;Inner Mongolia; spatial and temporal change

\section{摘要}

本研究以统计和地理信息系统技术为主要研 究方法, 研究内蒙古沙尘暴时空分布特征, 通 过分析从大范围沙尘天气的特征及通过对较 长时间尺度的沙尘暴移动路径进行观测和统 计分析, 有重要的科学意义以及研究价值。研 究结果表明: (1) 内蒙古境内近 35 年沙尘暴 日数波动中呈现减少趋势。其中, 各年代变化 上, 主要高频发期为 20 世纪 80 年代及 21 世 纪。(2) 近 30 年内蒙古境内 42 个站点 1981-2014 年沙尘暴空间分布特征为自西向东 
递减的趋势。1980-1999 年内蒙古沙尘暴高频 发区主要集中在阿拉善盟拐子湖及海力素两 地; 2000 年之后内蒙古境内出现了新的沙尘 暴高频发区, 即内蒙古锡林郭勒盟苏尼特左旗 及周围地区; 2001-2014 年沙尘暴高发区主要 以拐子湖、海力素以及苏尼特左旗为中心。上 述三个地区 2000-2005 年发生沙尘暴的次数占 全区发生频次的 $90 \%$, 其中锡林郭勒盟 12 个 站点的沙尘暴发生日数占了 $50 \%$ 以上。这与该 地区下垫面特征与气候条件有密切关系, 上述 地区多沙漠沙地, 大风日数多且风速较高, 地 表植被覆盖地较低; 发生次数最少的是内蒙古 东部及东北地区, 即呼伦贝尔盟及兴安盟, 此 处地表植被覆盖度较好, 年均降水量最高, 地 表沙土较不易被大风吹起而导致沙尘暴。

关键词: 沙尘暴; 内蒙古; 时空变化

\section{1. 引言}

沙尘天气是指大风将地面尘土、沙粒卷入 空中, 使空气混浊, 是干旱、半干旱地区发生 的具有突发性、破坏力强的灾害性天气现象, 包括浮尘、扬沙、沙尘暴、强沙尘暴和特强沙 尘暴, 能在短时间内给自然环境和社会经济造
成严重损失。全球沙尘暴易发生地区主要是中 亚、中非、北美和澳大利亚 ${ }^{[1]}$ 。我国沙尘暴易 发生区为包括有西藏、新疆、内蒙古、甘肃、 青海等广大北方地区，面积共占全国总面积的 $65 \%{ }^{[2]}$ 。其中, 内蒙古的沙尘暴主要通过西北 路和北路两条路径影响下游的京津地区, 该地 区强沙尘暴约有三分之一影响到京津地区, 约 有三分之二的特强沙尘暴对该地区构成威胁, 会引起扬沙、浮尘甚至沙尘暴天气 ${ }^{[3-4]}$ 。掌握 内蒙古国沙尘暴的空间分布规律和时间变化 特征对提高我国沙尘暴预报、预警及沙尘暴风 险评价提供科学依据, 对我国北方生态安全屏 障的环境保护和防风固沙等问题提供了科学 依据, 具有重要的社会和经济意义。

\section{2 研究区概况}

内蒙古自治区, 地理位置为东经 $94^{\circ} 07^{\prime}-124^{\circ} 31^{\prime}$, 北纬 $39^{\circ} 47^{\prime}-52^{\circ} 30^{\prime}$ 之间, 如图 1 所示。东起东经 $126^{\circ} 04^{\prime}$, 西至东经 $97^{\circ} 12^{\prime}$, 横跨经度 $28^{\circ} 52^{\prime}$, 东西直线距离 2400 多公里; 南起北纬 $37^{\circ} 24^{\prime}$, 北至北纬 $53^{\circ} 23^{\prime}$, 纵占纬度 $15^{\circ} 59^{\prime}$, 直线距离 1700 公里; 全区 总面积 118.3 万平方公里, 占中国土地面积的

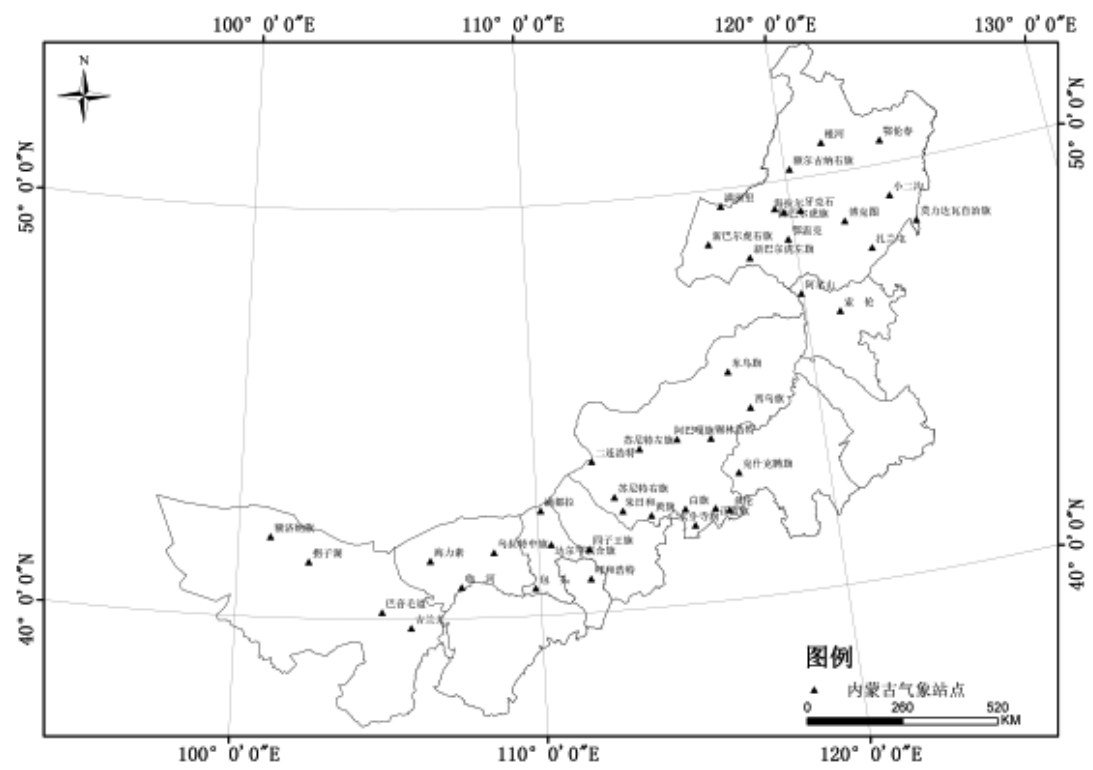

图 1. 研究区 


\section{Risk Analysis and Crisis Response in Big Data Era (RAC-16)}

$12.3 \%$, 是中国第三大省区。东、西、南边与 8 个省区毗邻, 跨三北 (东北、华北、西北), 与京津地区较近; 北部同蒙古国和俄罗斯联邦 接壤, 国境线长 4200 公里。

\section{3数据来源与处理}

研究区的数据资料主要在内蒙古气象局 提供的内蒙古自治区 42 个地面观测站 1980-2014 年 (1-12 月) 沙尘暴逐日观测数据 的基础上, 运用数理统计法以及空间插值法, 对时间序列、空间分布进行分析研究。

\section{4内蒙古沙尘暴特征研究}

\section{1时间变化}

\subsection{1年内变化}

从沙尘暴日数年内变化图（图 2) 中可以 得出, 沙尘暴天气发生在 3-5 月的频次最多, 这三个月沙尘暴发生的频次约占全年总发生 日数的 $79.48 \%$ 。其次是 6 月份发生的也较多, 约占 $8.8 \% ； 7 、 8$ 月是地表植被覆盖度最好的 季节, 降水量也是全年最高的时期, 因此大风 天气, 风速较低时比较不易扬起地面沙尘, 沙 尘暴频次相比春季要少 ${ }^{[5]}$; 秋季 (9-11) 是全 年发生频次最低的季节, 冬季 12 月至 2 月比 秋季稍多但也是发生沙尘天气较少的季节。

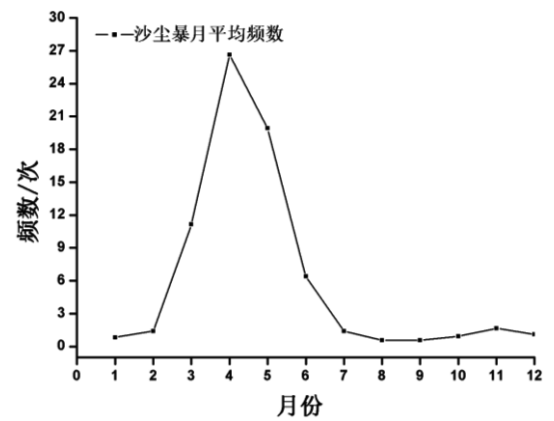

图 2. 1983-2014 年内蒙古沙尘暴发生日数 年内变化图

\subsection{2 季节变化}

将内蒙古境内 42 个站点的 1981-2014 年 沙尘暴年日数按季节统计可以得出（表 4-3),
内蒙古沙尘暴主要发生在春季 (3-5 月), 春季 沙尘暴发生的次数明显比其他季节要高很多, 约占全区年均沙尘暴总日数的 $70 \%$; 其次是夏 季, 有 $18 \%$, 秋季 $7 \%$; 冬季发生次数最少, 占 5\% (图 3-上)。

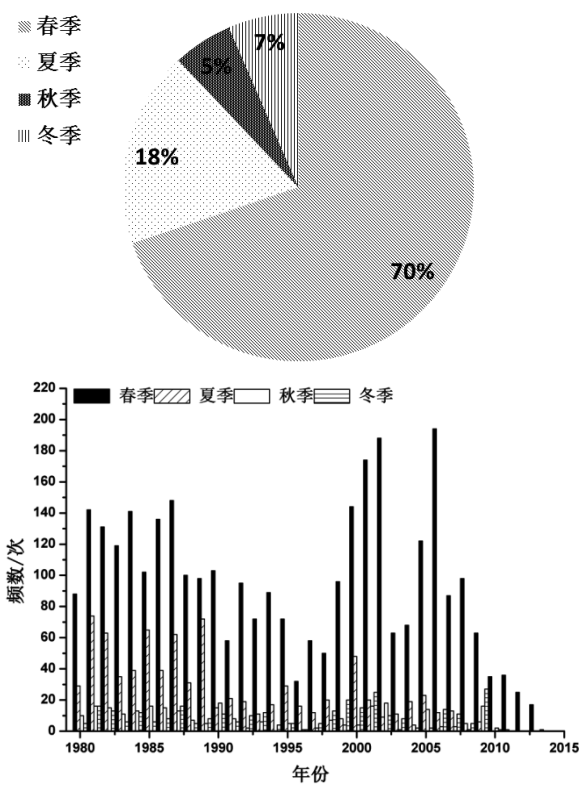

图 3. 内蒙古 42 个站点 1981-2014 年沙尘暴 年日数季节变化

从各季节沙尘暴发生总日数的年分布情 况得出 (图 3-下), 除了冬季发生日数变化较 为平缓, 其他三个季节均呈减少趋势。其中春 季沙尘暴发生日数是 1980-1990 年较多且每年 发生次数差别不大，1991-2000 年较少，2001 年以后发生日数出现最高值, 2007 年以后呈 现减少的趋势; 夏季沙尘暴发生日数变化在总 趋势上与春季基本一致, 但最高值出现在 1980-1990 年期间, 2001 年也较多, 其他年份 发生日数均较少; 秋冬季变化整体也与总趋势 基本一致，最高值出现在 1999-2002 年期间。

\subsection{3 年际变化}

统计了内蒙古 1980-2014 年边境地区 42 个观测站沙尘暴发生日数年际变化图上可以 看出, 内蒙古境内近 35 年沙尘暴日数波动中 
Risk Analysis and Crisis Response in Big Data Era (RAC-16)

呈现减少趋势。其中，1980-2000 年沙尘暴日 数变化呈现明显减少趋势, 发生日数最多的年 份是 1984 年、1990 年; 2001-2008 年急剧上

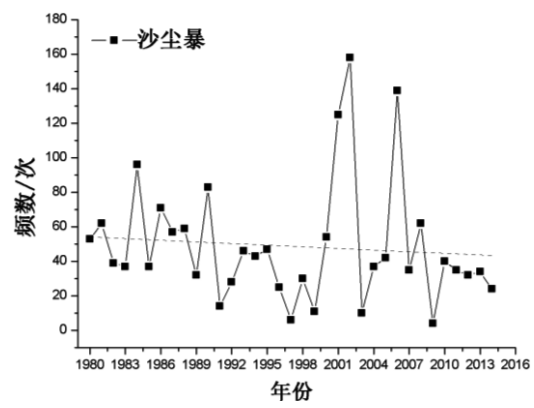

图 4. 1983-2014 年内蒙古沙尘暴发生日数 及趋势

升, 发生了 833 次沙尘天气, 影响范围较广。 2002 年之后沙尘天气发生次数大幅下降, 2006 年又急剧上升, 2007-2014 年沙尘暴日数有明 显减少趋势。

\subsection{4 年代际变化}

从内蒙古境内 1980-2014 年 42 个站点不 同年代沙尘暴发生总日数的统计中可以看出, 1980-1989 年共发生 1715 次, 1990-1999 年发 生 971 次, 2000-2009 年发生 1431 次, 2010-2014 年总计发生 448 次（表 1)。从 1980 年至今，1980-1989 和 2000-2009 年这两个时 期为明显的沙尘暴高发期，1990-1990 年发生 日数较少,约为 1980-1989 年间发生日数的 $1 / 2$, 2010 年后沙尘暴天气发生日数有急剧下降的 趋势。

表 1. 内蒙古 43 个站点各年代沙尘暴发生 日数统计

\begin{tabular}{llll}
\hline $1980-$ & $1990-$ & $2000-$ & $2010-$ \\
1989 & 1999 & 2009 & 2014 \\
\hline 1715 & 971 & 1431 & 448 \\
\hline
\end{tabular}

\section{2空间变化}

近 30 年内蒙古境内 42 个站点的沙尘暴发 生的情况各盟市有所不同。从图 5 可以看出, 其中额济纳旗拐子湖发生日数最多, 其次是巴
彦淖尔巴音温都苏木海力素。这两个地方年均 气温高、雨量少、蒸发量大, 自然环境较恶劣, 发生沙尘暴的日数分别占全区总发生日数的 $16 \%$ 和 $11 \%$, 为内蒙古西部区域阿拉善盟内两 个沙尘暴高频发区域; 其次是内蒙古锡林郭勒 盟。除了多伦县、太仆寺旗、东乌珠穆沁旗和 西乌珠穆沈旗因植被覆盖状况和降水量良好, 发生沙尘天气的次数较少之外, 其他各旗县沙 尘暴发生日数均较多, 尤其是属于荒漠草原的 锡林郭勒盟中西部地区, 可以看该区域内受到 沙尘暴的影响范围较广; 其次是呼和浩特、包 头等地区, 该区域沙尘暴天气主要是受到西部 和北部沙尘暴的影响; 发生次数最少的是内蒙 古东北地区，呼伦贝尔及兴安盟。

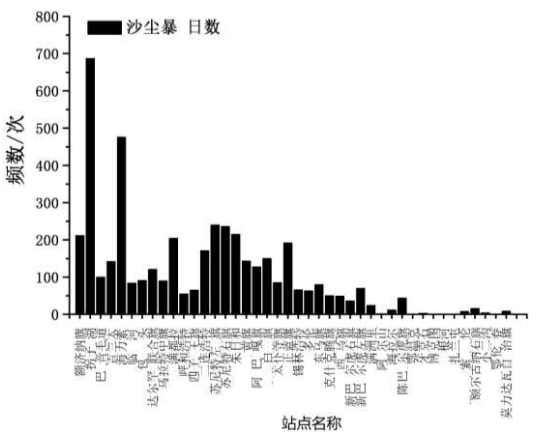

图 5. 内蒙古境内 42 个观测站沙尘暴发生情 况

根据内蒙古地区近三十年沙尘暴的年际 变化，做了相应的空间分布图加以分析。从 1981-2014 年沙尘暴空间分布(图 6-A) 看出, 整体呈现自西向东递减的趋势。内蒙古的沙尘 暴主要发生在中西部地区, 其中主要集中在阿 拉善盟额济纳旗、阿拉善右旗等北部地区及巴 彦淖尔市乌拉特后旗及其附近地区等属高发 地区, 近三十年发生了共 308 次、239 次、120 次。上述区域内包括中国四大沙漠内的巴丹吉 林沙漠、腾格里沙漠、乌兰布和沙漠，大风日 数较多, 具备发生沙尘天气的下垫面条件和气 候条件, 因此发生频次较多。其次是锡林郭勒 盟中西部地区, 主要是浑善达克沙地及其周围 地区共发生了 489 次。第三是内蒙古兴安盟以 及呼伦贝尔市以西的新巴尔虎和满洲里等与 蒙古国南部东方省接壤的地区共发生了 229 次。该区域内有内蒙古的两大沙地, 与西部地 


\section{Risk Analysis and Crisis Response in Big Data Era (RAC-16)}

区相比沙尘天气发生次数较少的原因是此处 是内蒙古年降水量最高的区域, 有较高的植被 盖度, 大风扬起地面沙尘较少, 大多数是内蒙 古西部地区及蒙古国南部地区沙尘暴的影响, 但总体发生频次不是特别多。为了更进一步了 解内蒙古沙尘暴空间分布的特征, 分了四个部 分来研究近三十年的变化。从图 6-B 中可以看 到, 1981-1990 年间, 除了 1980 年代末发生沙 尘暴次数较少以外, 直到 90 年代初, 一直处 于沙尘暴天气频发的状态。发生最多的地方是 位于巴丹吉林沙漠北部的拐子湖、海力素、额 济纳旗等西部地区; 90 年代初至 2000 年（图 6-C)发生的沙尘暴天气相对较少, 高频发区域 与上 10 年基本一致; 2001-2014 年 (图 6-D), 沙尘暴高频发区集中在内蒙古中西部高发区 有四个。即额济纳旗、拐子湖、海力素及苏尼 特左旗为中心的地区。

\section{3 内蒙古沙尘暴高频发区变化分析}

从图 4-7 可以看出沙尘暴空间分布的一个
明显的变化, 2000 年之前, 内蒙古沙尘暴集 中在西部, 2000 年以后出现了新的高频发区, 即除了巴丹吉林沙漠北部地区, 浑善达克沙地 及其周围地区成了沙尘暴发生日数较多地区, 因此内蒙古境内出现了 3 个高频发区, 中心分 别是: 海力素、拐子湖及苏尼特左旗。上述三 个地区 2000-2005 年发生沙尘暴的次数占全区 发生频次的 $90 \%$, 其中苏尼特左旗及周围地区 12 个站点的沙尘暴发生日数占了总发生日数 的 $50 \%$ 以上。而锡林郭勒盟浑善中西部区域的 沙尘暴对京津地区影响和危害更严重。 2006-2014 年沙尘暴主要集中在上述高频发地 区并逐步往东、南扩大。

\section{5.结论}

（1）从年内变化得出，内蒙古沙尘暴 $70 \%$ 发生在春季; 年际变化上, 内蒙古境内近 35 年沙尘暴日数波动中呈现减少趋势。其中, 1980-2000 年沙尘暴日数变化呈现明显减少趋

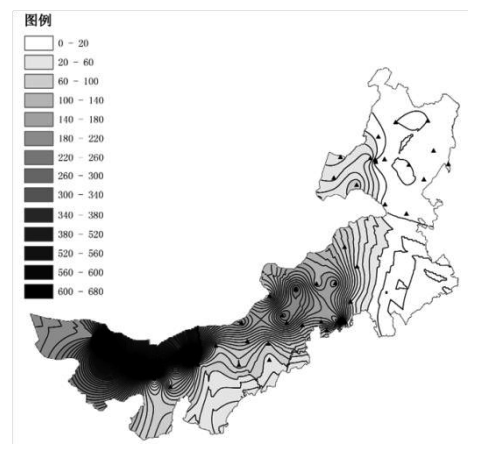

A $\quad 1981-2014$

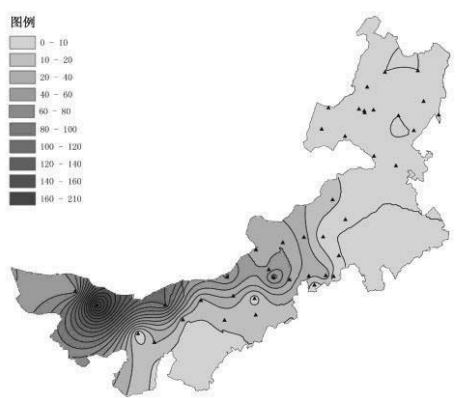

C $\quad 1991-2000$

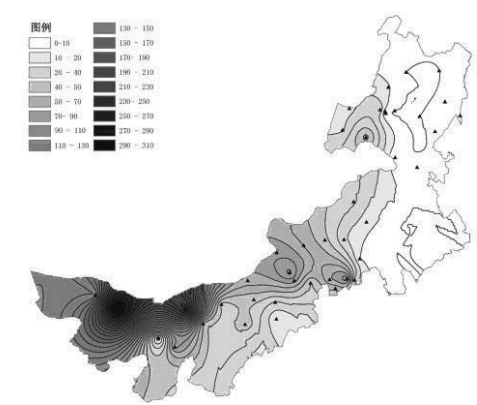

B $\quad 1981-1990$

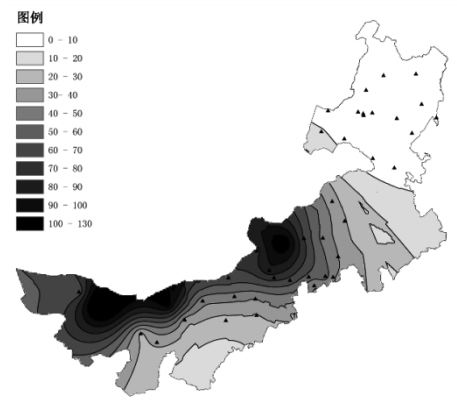

D 2001-2014

图 6 内蒙古沙尘暴 (1981-2014 年) 空间分布图 
Risk Analysis and Crisis Response in Big Data Era (RAC-16)

势, 发生日数最多的年份是 1984 年、1990 年; 2001-2008 年是内蒙古自治区沙尘暴天气最频 发的一个时期。其中 2001- 2002 年沙尘暴日数 急剧增加, 之后大幅下降, 2006 年又呈上升 趋势，2007-2014 年沙尘暴日数有明显减少趋 势; 年代变化上，1980-1989 年共发生 1715 次，1990-1999 年发生 971 次, 2000-2009 年发 生 1431 次, 2010-2014 年总计发生 448 次, 主 要高频发期为 20 世纪 80 年代及 21 世纪初。

(2) 近 30 年内蒙古境内 42 个站点 1981-2014 年沙尘暴空间分布特征为自西向东递减的趋 势。1980-1999 年内蒙古沙尘暴高频发区主要 集中在阿拉善盟拐子湖及海力素两地; 2000 年之后内蒙古境内出现了新的沙尘暴高频发 区, 即内蒙古锡林郭勒盟苏尼特左旗; 2001-2014 年沙尘暴高发区主要以拐子湖、海 力素以及苏尼特左旗为中心。上述三个地区 2000-2005 年发生沙尘暴的次数占全区发生频 次的 $90 \%$, 其中锡林郭勒盟 12 个站点的沙尘 暴发生日数占了 $50 \%$ 以上。这与该地区下垫面 特征与气候条件有密切关系, 上述地区多沙漠 沙地, 大风日数多且风速较高, 地表植被覆盖 地较低; 发生次数最少的是内蒙古东部及东北 地区, 即呼伦贝尔盟及兴安盟, 此处地表植被 覆盖度较好, 年均降水量最高, 地表沙土较不 易被大风吹起而导致沙尘暴。

\section{Acknowledgements}

This study was supported by National "Twelfth Five-Year" Plan Project for Science and Technology Support (No. 2013BAK05B01) and Natural Science Foundation the of Inner Mongolia Autonomous Region (No.2013ZD08, No.2013MS0616), and Inner Mongolia Normal University major project to cultivate special project(No.2013ZDPY04) and oppening subject of Key Laboratory of Vegetation Ecological Sciences, Ministry of Education.

\section{致谢}

本研究得到了资助项目: “十二五” 科技支撑 计划项目资助 (2013BAK05B01) 内蒙古自治区 自然基（2013ZD08、2013MS0616）和内蒙古师
范大学重大项目培育专项项目（2013ZDPY04） 以及植被生态科学教育部重点实验室的开放 课题的支撑。

\section{参考文献}

[1] Pye, K.Aolian dust and dust deposits. Acdamic Press Inc.Ltd., London, 1987: 113-126.

[2] 潘耀忠, 范一大, 史培军, 顾晓鹤. 近 50 年来中国沙尘暴空间分异格局及季相分 布的初步研究. 自然灾害学报, 2003, 01:1-8.

[3] 高涛.内蒙古沙尘暴的调查事实、气候预 测因子分析和春季沙尘暴预测研究.内蒙 古气象, 2008,2,3-11.

[4] 彭珂珊. 沙尘暴对西部发展的危害研究. 地质技术经济管理，2004，03:19-25.

[5] 咏 梅; B. Munkhdorj; 包玉 海; Shiirev-Adiya; Battsengel.近 10 年蒙古国 沙尘暴气候特征分析(英文). 风险分析和 危机反应中的信息技术--中国灾害防御 协会风险分析专业委员会第六届年会论 文集，2014，655-660. 